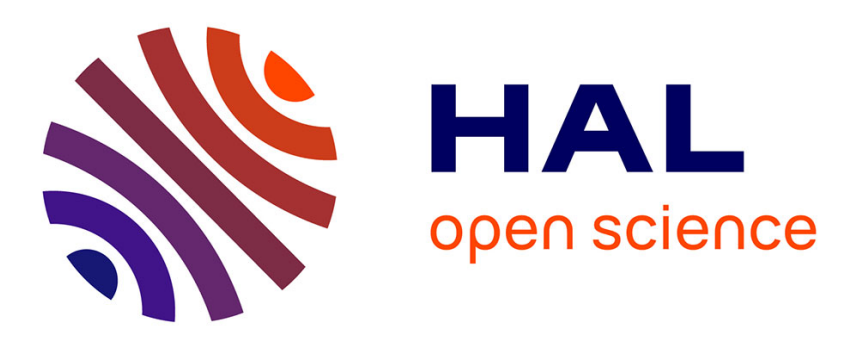

\title{
The interacting effect of habitat amount, habitat diversity and fragmentation on insect diversity along elevational gradients
}

Niry T Dianzinga, Marie-Ludders Moutoussamy, Joëlle Sadeyen, Lala H R Ravaomanarivo, Enric Frago

\section{To cite this version:}

Niry T Dianzinga, Marie-Ludders Moutoussamy, Joëlle Sadeyen, Lala H R Ravaomanarivo, Enric Frago. The interacting effect of habitat amount, habitat diversity and fragmentation on insect diversity along elevational gradients. Journal of Biogeography, In press, 10.1111/jbi.13959 . hal-02959759

\section{HAL Id: hal-02959759 \\ https://hal.inrae.fr/hal-02959759}

Submitted on 7 Oct 2020

HAL is a multi-disciplinary open access archive for the deposit and dissemination of scientific research documents, whether they are published or not. The documents may come from teaching and research institutions in France or abroad, or from public or private research centers.
L'archive ouverte pluridisciplinaire HAL, est destinée au dépôt et à la diffusion de documents scientifiques de niveau recherche, publiés ou non, émanant des établissements d'enseignement et de recherche français ou étrangers, des laboratoires publics ou privés.

\section{(ㅇ)(1) $\$$}

Distributed under a Creative Commons Attribution - NonCommerciall 4.0 International 


\title{
The interacting effect of habitat amount, habitat diversity and fragmentation on insect diversity along elevational gradients
}

\author{
Niry T. Dianzinga ${ }^{1,2}$ | Marie-Ludders Moutoussamy ${ }^{1}$ | Joëlle Sadeyen ${ }^{2}$ | \\ Lala H. R. Ravaomanarivo ${ }^{3}$ | Enric Frago ${ }^{1,4,5}$ (D)
}

${ }^{1}$ CIRAD-UMR PVBMT, Saint-Pierre, La Réunion, France

${ }^{2}$ Université de la Réunion-UMR PVBMT, Saint-Denis, La Réunion, France

${ }^{3}$ Département d'Entomologie, Faculté des Sciences, Université d'Antananarivo, Antananarivo, Madagascar

${ }^{4}$ CIRAD, CBGP, Montpellier, France

${ }^{5}$ CBGP, CIRAD, INRA, IRD, Montpellier SupAgro, University Montpellier,

Montpellier, France

\section{Correspondence}

Enric Frago, CIRAD/UMR CBGP, 755 avenue du campus Agropolis - CS30016 34988

Montferrier sur lez cedex, France

Email: enric.frago@cirad.fr

Funding information

Centre de Coopération Internationale en Recherche Agronomique pour le Développement; European 490 Union (EAFRD and ERDF programs); Regional Council of Reunion; Departmental Council of the Region Reunion; Agence Nationale de la Recherche

Handling Editor: Ole Vetaas

\section{Handing Editor. Ole Vetaas}

\begin{abstract}
Aim: Elevational gradients are a useful approach to evaluate how environmental factors affect animal diversity. Decades of studies on the elevation-diversity gradient have revealed that this gradient varies greatly with taxa and geographic regions. One potential explanation for this may be the dependence of the relationship on landscape features. We explore the impact of fragmentation, habitat diversity and habitat amount on insect diversity (alpha and beta) and abundance along elevational gradients. We hypothesize that insect diversity and abundance will relate negatively with elevation, but positively with these landscape features. We also hypothesize that landscape features will interact in a way that the positive effect of a given variable on insect diversity may be offset by the others.

Location: Reunion Island (Indian Ocean).

Taxon: The insect order thrips (Thysanoptera).

Methods: Insects were sampled along replicated elevational gradients, and at each sampling plot landscape features and abiotic variables were estimated within buffers surrounding the site. Insect alpha diversity was estimated using abundance-based rarefaction methods, whereas beta diversity was estimated calculating the "Local contributions to beta diversity" metric. The effect of elevation, rainfall, landscape features and their interactions was assessed on insect alpha and beta diversity and abundance during two consecutive seasons using linear mixed effects models.

Results: We found that thrips alpha and beta diversity was negatively related with elevation, but the relationship varied between seasons and rainfall regimes. Among the different landscape features considered, we found that habitat amount had the strongest effect on diversity. The effect of habitat amount on diversity, however, was offset in areas of low habitat (or land cover) diversity.
\end{abstract}




\section{KEYWORDS}

alpha diversity, beta diversity, elevational gradient, environmental gradient, multi-scale analysis, barcoding, seasonality, insect, thrips, Thysanoptera

\section{1 | INTRODUCTION}

It is nowadays widely accepted that human activities are triggering unprecedented biodiversity losses in most terrestrial ecosystems. Human activities usually have a negative impact on biodiversity by directly degrading and transforming natural habitats, but also indirectly through changes in global climatic conditions (Barnosky et al., 2011; Cardinale et al., 2012; Hooper et al., 2012; Urban, 2015). By comparing diversity across space and assessing its changes in relationship with climate, relief and landscape configuration ecologists seek to understand and predict large-scale impacts of human activities on biodiversity. To achieve this, elevational gradients are useful because assemblages of species found at very different conditions can be studied within small geographic distances (Hodkinson, 2005; Sundqvist, Sanders, \& Wardle, 2013; Tylianakis \& Morris, 2017) Several environmental factors vary with elevation leading to lower plant species richness and structural complexity at higher elevations (Kreft \& Jetz, 2007). This elevation-diversity gradient is observed in insects because they are affected by environmental factors too, but also because they tightly depend on plants. This gradient, however, often varies with climatic regions and insect taxa (Chamberlain, Brambilla, Caprio, Pedrini, \& Rolando, 2016; McCain, 2009; Sundqvist et al., 2013). Most studies have explored how species richness and evenness (i.e. alpha diversity) change with elevation, and there is an increasing interest in how species composition (i.e. beta diversity) changes along with these gradients. While alpha diversity expresses net diversity differences among species assemblages, through the lens of beta diversity, differences in the composition of insect assemblages can be assessed, and areas where unique species are found may be pinpointed (Mori, Isbell, \& Seidl, 2018; Socolar, Gilroy, Kunin, \& Edwards, 2016).

The elevational-diversity gradient was already noticed by Alexander von Humboldt in the 18th century, and since then it has been intensively studied with mixed and often contradictory results. Generalizing the factors underlying this gradient across taxa and geographic regions has become a cornerstone in ecological theory, particularly because it can help to assess and to forecast the impact of human activities on diversity (Hodkinson, 2005; Sundqvist et al., 2013; Tylianakis \& Morris, 2017). The elevational-diversity gradient varies greatly with taxonomic groups and climatic regions because the impact of elevation on diversity depends on complex interactions among environmental variables and habitat and landscape characteristics (Chamberlain et al., 2016; McCain, 2009; Sundqvist et al., 2013). This variation also depends on human activities, which are usually greater at lower elevations where human populations concentrate (Luck, 2007). Landscape features have known impacts on insect diversity and are thus important to understand the elevation-diversity gradient. The most important landscape features with known impacts on animal diversity are habitat diversity, habitat amount and fragmentation. As revealed in a meta-analysis by Stein, Gerstner, and Kreft (2014), diverse or heterogeneous habitats often contain a larger number of species because they provide a larger range of abiotic conditions, available niches and refuges. These conditions ultimately allow species coexistence, reduce extinctions and promote speciation. Habitat diversity has been strongly reduced by human activities particularly due to the homogenizing effect of extensive cropping, forestry and livestock production (Kremen \& Merenlender, 2018). Despite the results found in the meta-analysis, evidence of negative or neutral effects of habitat diversity on species diversity also exist (Bertrand, Burel, \& Baudry, 2016; Marini, Prosser, Klimek, \& Marrs, 2008). The effect of habitat amount on diversity, on the other hand, is clearly positive. When the amount of habitat that species can exploit is reduced, species struggle to persist because resources are of less quality and less abundant, and because critical resources may be lacking (Samways, McGeoch, \& New, 2010). Habitat loss is one of the landscape features most strongly influenced by human activities, and is considered as one of the main drivers of current biodiversity loss (Cardinale et al., 2012; Mantykapringle, Martin, \& Rhodes, 2012). Fragmentation too affects species diversity, although whether the effect is positive or negative remains a controversial topic. Human activities are important drivers of fragmentation. Fragmented landscapes are often composed of small patches of natural habitat surrounded by urban, agricultural or timber-producing lands. Most authors consider that fragmentation has a negative effect on species diversity (Fletcher et al., 2018) because it increases the division and isolation of natural habitats thus exposing them to disturbing human land uses (Haddad et al., 2015). Fahrig (2017, 2019), however, suggests that since habitat fragmentation often comes together with habitat loss, when the amount of habitat available for organisms to exploit is taken into account (an estimate known as fragmentation per se [sensu Haila and Hanski (1984)]), the negative effect of fragmentation is lost. This idea was proposed as the habitat amount hypothesis (Fahrig, 2013) [but see criticism by Fletcher et al. (2018) and Hanski (2015)], where she suggests that habitat amount and fragmentation can be measured independently so that their relative contribution to diversity can be estimated. A meta-analysis that encompasses 35 studies from different locations around the globe has recently provided support for this hypothesis (Watling et al., 2020).

Human impacts on natural habitats vary in intensity with elevation, but their effect on different landscape features is often intricate. For instance, while most human populations concentrate at lower elevations (Luck, 2007), food, timber and livestock production usually concentrates at particular elevational ranges, with concomitant effects on habitat diversity and fragmentation. Even if diversity usually decreases with elevation, speciation and endemism may be 
larger at high elevations where habitats are more isolated and, in temperate areas, more fragmented due to glacial advances and retreats (Steinbauer et al., 2016; Vetaas \& Grytnes, 2002). In addition, landscape features are usually interconnected. The positive effect of fragmentation on species diversity, for instance, may be linked to habitat diversity because fragmented landscapes are usually more heterogeneous and structurally more complex (Fahrig, 2017). A recent theoretical model showed that habitat amount modulated fragmentation effects on diversity so that fragmentation effects were positive when the amount of habitat was large, but negative when habitat amount was reduced (Rybicki, Abrego, \& Ovaskainen, 2020). In another example, Corcos et al. (2018) found that the diversity of four different insect guilds was affected both by elevation and habitat diversity, but the effect of one variable never modulated the effect of the other. Despite all these recent reports, few studies have so far measured the relative contribution of different landscape attributes to diversity (Fahrig, 2019; Hanski, 2015), and how they interact with elevation. This knowledge is important to evaluate whether diversity changes along elevation are mostly driven by abiotic conditions or the local landscape. Exploring interacting effects among landscape attributes is particularly important to better understand whether the impact of habitat loss may be exacerbated or buffered by changes in habitat diversity or fragmentation. This knowledge may ultimately help better transferring biogeography theory into conservation and management practice.

In this study we explore the relative contribution of elevation, environmental variables and landscape features to Thysanoptera (i.e. thrips) diversity. Thrips are slender insects, of approximately 1 to $3 \mathrm{~mm}$ long with about 6.000 extant species described worldwide (Stork, 2018). Thrips larvae can be herbivorous, predatory or fungivorous, and many species disperse to flowers as adults to feed on pollen or to mate (Mound, 2005). This study was performed in Reunion, a small volcanic island located in the south-western Indian Ocean. Local-landscape characteristics were obtained by estimating habitat diversity, habitat amount and fragmentation using highly-resolved vector layers and establishing buffers around sampling points. Habitat diversity was assessed as land cover diversity (Stein et al., 2014), fragmentation as the length of the perimeter of the different polygons found within the buffer, and habitat amount as the proportion of potentially suitable habitat within the buffer (Watling et al., 2020). Since insects were sampled from flowers and during two consecutive seasons, the role of the plant, season and rainfall were also taken into consideration. The following hypotheses are tested (Figure 1): (a) We hypothesize that alpha diversity (i.e. species richness and evenness), insect abundance and beta diversity will decrease with elevation. (b) We hypothesize that habitat amount and habitat diversity will relate positively with insect diversity and abundance. Since the proportion of suitable habitat is taken into account in our study, our estimate of fragmentation can be considered as fragmentation per se, and we thus hypothesize that this feature too will relate positively with insect diversity and abundance. (c) We also explore interactions among the different landscape features, and in particular whether the relationship between habitat amount and variables related to insect diversity and abundance is modulated by either habitat diversity or fragmentation. We hypothesize that the positive effect of habitat amount on insect diversity may be offset in low diversity habitats Fragmentation, on the other hand, may have an either positive or negative effect on the relationship between habitat amount and species diversity. The interaction between habitat diversity and fragmentation may provide a better understanding

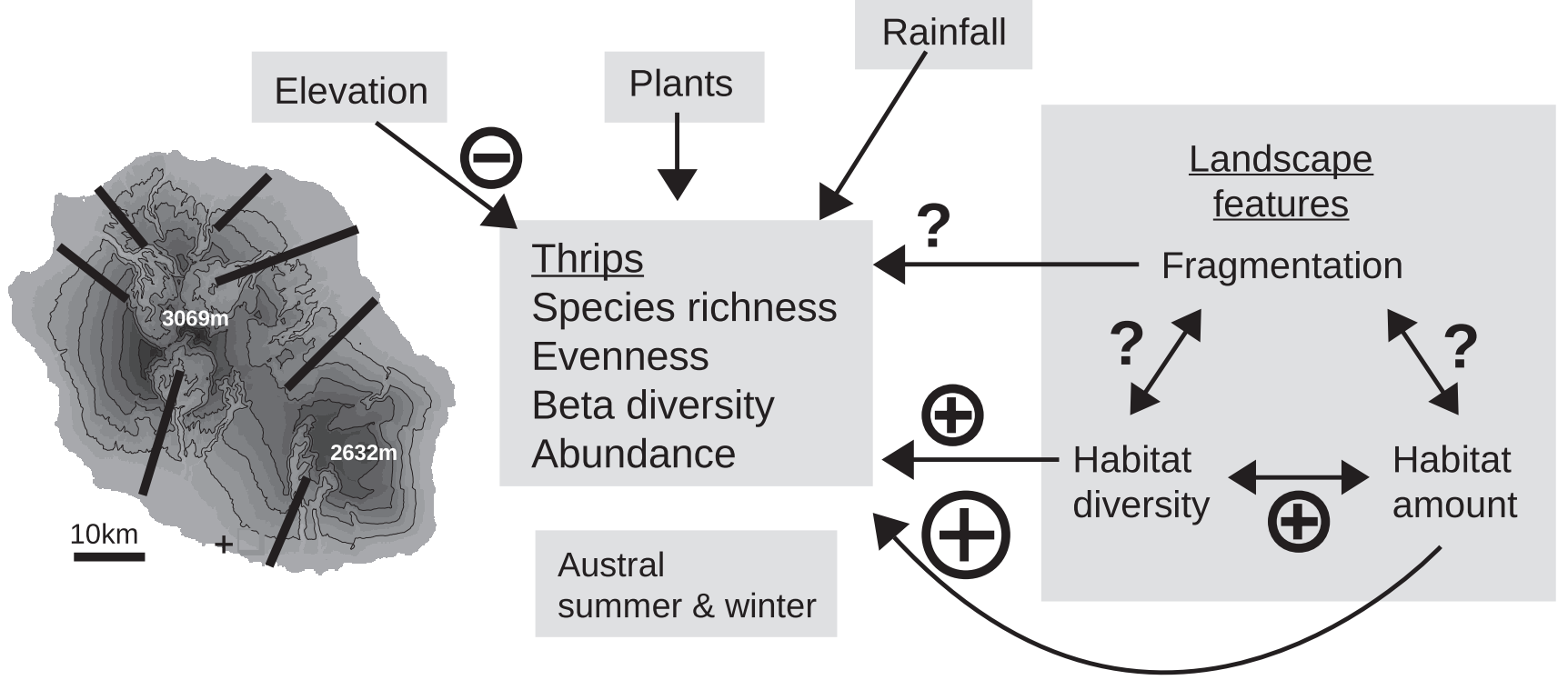

FIGURE 1 Conceptual diagram of the experimental design and variables tested in this study. Arrows point from predictor to response variables, whereas double-headed arrows indicate interactions between landscape variables. Positive and negative symbols represent our a priori hypotheses on the effect of elevation,landscape features, and their interactions on insect diversity and abundance. Larger positive symbols represent expected stronger effects on diversity and abundance, whereas question marks are shown when no directional hypothesis is proposed. A map of Reunion island with $500 \mathrm{~m}$ contour lines and the location of transects is also shown. 
of whether fragmentation effects operate via changes in habitat diversity.

\section{2 | MATERIALS AND METHODS}

\section{1 | Study system}

In this study, adult insects belonging to the order Thysanoptera (i.e. thrips) were sampled from flowers along replicated elevational gradients that run across different habitat types. Thrips are small insects with about 6.000 extant species (Stork, 2018), and were sampled from flowers because even if larvae can be herbivorous, predatory or fungivorous, many species feed on pollen or disperse to flowers for mating (Mound, 2005). This study was performed in Reunion, which is located at $55^{\circ} 39^{\prime} \mathrm{E}, 21^{\circ} 00^{\prime} \mathrm{S}$ in the south-west of the Indian Ocean between Madagascar and Mauritius with $2,512 \mathrm{~km}^{2}$ of surface. The island has a maximum diameter of $70 \mathrm{~km}$. Its rugged terrain reaches 3,070 m.a.s.l. and 2,631 m.a.s.l. in the Piton des Neiges and Piton de la Fournaise, respectively. The island has a tropical climate with two seasons: summer and winter. The former occurs from November to April and it is rainy and hot, while the latter occurs from June to September and it is less hot and dryer. Climatic conditions are strongly dependent on the topography and trade winds (i.e. regular ocean winds blowing from East to West). Mean annual rainfall is higher in the eastern part (windward coast) with $1,500 \mathrm{~mm}$ to $>8,000 \mathrm{~mm}$, whereas in the western part (leeward coast) annual rainfall varies between $<500 \mathrm{~mm}$ to $<1,500 \mathrm{~mm}$ Mean annual temperatures are of $24^{\circ} \mathrm{C}$ near the coastline, and they can descend to $<12^{\circ} \mathrm{C}$ at 2,000 m.a.s.l. This island is considered a global hot-spot of diversity (IUCN, 2008) and is typified by a high level of endemism, with $46 \%$ of its 1.712 species of vascular plants endemic and with eight endemic genera. Among arthropods, it is estimated that $40 \%$ of beetles and $25 \%$ of spiders are also endemic (IUCN, 2008). Urbanization and agricultural activities are mostly concentrated below $1,000 \mathrm{~m}$, while the largest proportion of natural habitats (c. $30 \%$ ) is mostly concentrated above $1,200 \mathrm{~m}$ in areas that are less inhabited and often protected under the umbrella of the National Park (Strasberg et al., 2005). As in most tropical islands (Harter et al., 2015; Russell \& Kueffer, 2019), the main threats to this biodiversity are global changes, urbanization, agriculture and alien plant invasions, the latter three being particularly important at low elevations (Strasberg et al., 2005).

\section{2 | Sampling design and insect collection}

Thrips were collected along seven replicated elevational transects (Figure 1). Transects were selected to capture landscape diversity and the different vegetation zones, and to ensure that landscape features varied with elevation but not collinearly. Reunion is a small island, and to avoid higher elevation points to converge, sampling took place below a mid elevation point of $1,600 \mathrm{~m}$. Three transects reached up to $1,400 \mathrm{~m}$, and four to $1,600 \mathrm{~m}$. Sampling sites were established every $200 \mathrm{~m}$ of elevation, these elevational ranges being approximate as sites were selected based on visual detection of abundant plants at the flowering stage. At each site, insects were sampled from all flowering plants in a circular area of $30 \mathrm{~m}$ of diameter using the beating sheet technique with a rectangular $40 \times 30 \mathrm{~cm}$ white plastic tray and a mouth aspirator. To standardize sampling effort per plant, each was sampled for $10 \mathrm{~min}$. Usually a single site per season, elevational range and transect was selected, but sometimes up to three sites per elevational range were established when few plants in bloom were found. Thrips were sampled in 2017 in summer (January to February, 64 sites) and winter (May to July, 56 sites) (Appendix S1) on sunny, dry and non-windy days from 9 a.m. to 3 p.m. Since most plants only bloom in one of the two seasons, sampling sites were not the same in winter and summer and the two seasons were therefore analysed independently. Sampling was carried out by N.T.D., M.-L.M. and E.F. To avoid any sampling bias, at each site sampling of the different plant species was randomly assigned to one of the three researchers. At each site, latitudinal and longitudinal coordinates were recorded, and elevation was obtained with the $\mathrm{R}$ function elevation from the package rgbif version 1.0.2.

In this study the unit of analysis was the assemblage of insects obtained from a given plant. Site was not the unit of analysis because the number of plants (and hence sampling effort) varied between sites. Plant flowers were thus microhabitats from where adults were obtained because even if adults of most species disperse to flowers to feed on pollen, or to mate, their larvae feed on other plant species, fungi, or on other arthropods (Mound, 2005). Taking the habitat amount hypothesis as an example (Fahrig, 2013), diversity patterns should be studied by exploring "the number of species in a plot of fixed size" and how they vary with "total habitat area in the "local landscape' surrounding the plot". In our study, flowers represent the plots of fixed size, whereas the information extracted from buffers (see below) represents the local landscape.

\section{3 | Morphological and molecular insect identification}

A short description of the methods used to identify insects is provided here, but more details can be found at Appendix S2. Insects were first identified morphologically by N.T.D and a subset of specimens barcoded to ensure identifications and to detect potential cryptic species. Based on their abundance and the potential presence of cryptic species [as in Frankliniella schultzei (Tyagi et al., 2017)], a total of 223 specimens representing four known endemic species [Thrips bourbonensis, T. candidus, T. quilicii and T. reunionensis n. sp (Goldarazena, Dianzinga, Frago, Michel, \& Reynaud, 2020) ] and six species with a global distribution (T. parvispinus, T. florum, Megalurothrips sjostedti, F. schultzei, Hercinothrips pattersoni and $\mathrm{H}$. gowdeyi) were barcoded. 196 sequences were obtained and new ones imported from NCBIGenBank (https://www.ncbi.nlm.nih.gov/genbank/) to build a phylogenetic tree using the maximum likelihood method. All specimens, 
sequenced voucher specimens and their DNA are currently stored at the entomological collections of CIRAD-UMR PVBMT (CIRAD, Saint-Pierre, La Réunion) and at Centre for Biology and Management of Populations (CBGP-INRA, Montpellier/Montferrier-sur-Lez, France).

\subsection{Estimation of landscape features and environmental variables}

Habitat diversity, habitat amount and fragmentation were obtained from five nested circular buffers surrounding sampling sites using a highly-resolved vector layer of Reunion Island land cover map (http:// aware.cirad.fr/layers/geonode\%3Aclassif_gabir_2016_2017). Vector-layer information was extracted using QGIS Desktop version 2.18.2 and then exported to R. The vector layer used contained nine habitat types: sugar cane, vegetable crops, forest, forest plantation, grassland, bare rock, savannah, orchards and urban habitats. Habitat diversity was estimated with the Shannon index as the proportional contribution of the nine habitat types within the buffer [i.e. land cover diversity, Stein et al. (2014)] using the function diversity from the package vegan]. Fragmentation was estimated as the length of the perimeter of the different polygons found within the buffer divided by the total surface of the buffer. Habitat amount was estimated as the proportion of the total surface of the buffer that was considered as habitat, a method recently proposed by Watling et al. (2020). Even if the information provided by land cover data can be complemented with additional site data (Betts et al., 2014) like plant diversity, land cover maps are ideal to capture the habitats potentially used by functionally-diverse animal groups. This is particularly true in this study given the different ecosystems studied, the abrupt landscape of the island, and the variable feeding habits of the insects studied (as explained above). Landscape features considered as non-habitats were urban areas, bare rock or the ocean (this latter case was common in sites located near the coast). Urban zones were not considered as thrips habitats because although some thrips species can be found in ornamental trees, the biomass of vegetation in these areas is usually low. If habitat amount is estimated considering urban zones as habitat, some minor differences are found, but the main results remain similar (results not shown). Environmental variables were obtained for each sampling site and season using the raster layers of average monthly data from 2007 to 2017 in Reunion Island (Météo-France, https://donneespubliques.meteofrance.fr/). The data obtained was mean, maximum and minimum annual temperature, and accumulated annual rainfall, which was extracted from raster layers using the function raster from the package raster version 2.7-15.

\section{5 | Statistical analyses and multi-scale analysis}

We performed all statistical analysis with $R$ software version 3.4.2 using several packages (see R package details in Appendix S3). Alpha diversity was estimated using abundance-based rarefaction methods to estimate Hill numbers (or effective number of species) and to take into account potential undetected species of thrips (Chao et al., 2014; Chao \& Jost, 2012; Colwell et al., 2012; Jost, 2006). Species richness and the Simpson index (i.e. evenness) were estimated as Hill numbers of order $q=0$ and $q=2$, respectively, using the iNEXT function from the package iNEXT. The package adespatial was used to assess the ecological uniqueness of each insect assemblage based on their contributions to global beta diversity, by calculating the 'local contributions to beta diversity' (LCBD) index (Legendre and De Cáceres, 2013). To test the effect of elevation, landscape features, and environmental variables on diversity and abundance estimates, linear mixed effects models were built with a Gaussian error distribution using the function Imer from the package Ime4. As explained above, in our study the unit of replication was the thrips obtained in a given plant. We assumed a linear relationship among variables as non-linear relationships were not observed (Appendix S4). An independent model was built for each of the following response variables: species richness (i.e. number of species), the Simpson index (or species evenness), beta diversity (the LCBD index), and insect total abundance. Given the large variation in environmental conditions during winter and summer, and that different sites were established during these two seasons, independent models were also built for the two different seasons studied. In each model plant identity, elevation, precipitation, fragmentation, habitat diversity, habitat amount, and pairwise interactions between landscape features were included as explanatory variables (Figure 1). As environmental variables, precipitation, minimum, mean and maximum temperatures were obtained, but only precipitation was retained in the models as the other variables were highly correlated with elevation (Pearson correlation $R \geq 0.95, p<0.001$, Appendix S5). Our study does not particularly focus on plant effects on thrips diversity and abundance, but this variable was included in all models as co-variable to account for this source of variability. Plants that were sampled less than five times during the whole study were considered as a single category (see details on sampled plants in Appendix S6). To account for the spatial autocorrelation between study sites, and for the non-independence of plants sampled in the same site, site nested within transect was included as a random effect. To further correct for any potential spatial autocorrelation a grid of cells of $0.09 \times 0.09$ decimal degrees was defined over the map. These cells were given a random identity, which was then included as a second random factor to ensure that the potential resemblance between nearby sites is accounted for. To improve model fit and interpretation, all continuous explanatory variables were standardized to mean and standard deviation equal to zero and one, respectively (Harrison et al., 2018). In the models for insect abundance, richness and Simpson diversity, the response variable was log transformed (expressed as log[response +0.5$]$ ) to satisfy model assumptions. In addition, the ImerControl function with the optmizer nloptwrap from the package nloptr was used to improve model performance (Bates, Mächler, Bolker, \& Walker, 2015). Model fit was assessed by visual inspection of the residuals. In the models for insect richness and evenness, model residuals revealed 
slight evidence of non-homogeneity, which was considered as having negligible effects on our model estimates as recently suggested by Schielzeth et al. (2020). The absence of data points with high influence was checked by calculating Cook's distances with the function CookD from the predictmeans package. Our models did not have any significant spatial autocorrelation among data points as revealed by the function Moran-I from the ape package. $p$-values were obtained with a Chi-square test, using the function ANOVA from the package car. Significant results were plotted using the function visreg from the visreg package, which allows plotting partial residuals plots from mixed effects models. The non-linear multidimensional scaling (NMDS) was used to visualize how thrips diversity is influenced by elevation, rainfall and landscape features, and also to visualize how specific insect species associate with specific plants or with particular environmental or landscape features. This analysis was performed by transforming data with the Hellinger transformation (Legendre and Anderson, 1999; Legendre and Gallagher, 2001) and using the capscale function from the package vegan version 2.5-1 . Since we had little information on dispersal capabilities of the studied insects, and thus of the scale at which they may be affected by landscape features (i.e. the scale effect), a multi-scale analysis was also performed. As suggested by Fahrig (2013), Jackson and Fahrig (2015) and Watling et al. (2020) this analysis was done by estimating the effect of landscape features using five nested circular buffers with five different radii from the centre of each sampling site: $100,300,600,1,000$ and $3,000 \mathrm{~m}$. These distances to the centre of the sampling site may represent short and long-distance dispersal of thrips. It is expected that the variance explained by the different landscape features in statistical models is highest for the scale that best fits the home ranges or life dispersal of the species studied. In this analysis, the variance explained by the models was obtained with the function r.squaredGLMM from the package MuMIn, and significance of a given landscape feature in the different models was tested by comparing simplified and complex models (see more details in the Appendix S12). For the models using the same response and predictor variables $p$-values were corrected for multiple testing using the false discovery rate method. This method is less stringent than other methods like Bonferroni, and is appropriate when a large number of comparisons are performed (Benjamini \& Hochberg, 1995).

\section{3 | RESULTS}

\section{1 | Morphological and molecular identification of thrips}

In this study, 4,280 specimens were collected and 4,261 identified to species level from flowers of 106 different plants: 86 exotic and 20 indigenous belonging to 44 families (Appendix S6). Insects were classified into 40 species, and we were unable to identify to species level 64 individuals (1.5\%), which belonged to 19 different morphospecies. Seventeen of these morphospecies were identified to genus level (Appendix S7). The three known endemic species were well-represented with 1964 Thrips bourbonensis,150 T. quilicii and $114 \mathrm{~T}$. candidus. A total of 329 specimens belonged to a species newly discovered in this study. This species has been named T. reunionensis n. sp (Goldarazena et al., 2020), and is very similar morphologically and at the molecular level to T. bourbonensis. Some widespread (and probably exotic) species were also very abundant, including Frankliniella schultzei with 518 individuals, Haplothrips gowdeyi with 381 individuals, Megalurothrips sjostedti with 199 individuals, and Hercinothrips pattersoni with 198 individuals. Association between plants and particular thrips species can be visualized in the non-linear multidimensional scaling analysis (NMDS, Appendix S8). For example, the newly discovered T. reunionensis (Goldarazena et al., 2020) was associated with the endemic plant Dombeya ficulnea, the endemic T. bourbonensis was mostly found at higher elevations, and the exotic and widespread F. schultzei was mostly found on the exotic plants Lantana camara, Solanum mauritianum and Ipomea indica. Maximum-likelihood trees (Appendix S9) mostly confirmed our morphological identifications. The endemic species T. bourbonensis, T. candidus, T. quilicii and T. reunionensis formed different clades, which were supported by $88,100,100$ and $100 \mathrm{Ml}$ bootstrap, respectively. However, two different evolutionary lineages were found for F. schultzei. Based on previous studies these two lineages were considered as different species and classified based on their colour (Tyagi et al., 2017). These lineages are known as F. schultzei la1, which is close to F. schultzei from India, and F. schultzei Ila1, which is close to F. cf. schultzei/sulphurea from Australia.

\subsection{Landscape changes along elevation and multi- scale analysis}

Transects run from 0 to 1,600 m.a.s.l., and along this gradient important landscape changes were reported (Appendix S10 and S11). The mean proportion of natural forest increased steadily with elevation from mean values of $25 \%$ at low elevations to more than $75 \%$ above 1,200 m.a.s.l. The proportion of urban areas followed the opposite pattern as low elevation sites were surrounded by landscapes containing between $40 \%$ and $50 \%$ of urban landscape, but this proportion decreased gradually to less than $10 \%$ at higher elevations. Although the mean proportion of sugar cane and of meadows never represented more than $25 \%$ of the area surrounding study sites, these two habitat types were important between 500 to 1,200 m.a.s.l. Savannas are common in the west of the island, and represented an average of around $25 \%$ at 200 m.a.s.l. The mean proportion of area occupied by orchards was more important at low elevations, but they never represented more than $10 \%$ of the area. Other habitat types including forest plantations, vegetable crops or bare rock never occupied more than $5 \%$ of the area surrounding study sites (Appendix S10).

The different landscape features measured also changed with elevation without any remarkable difference when estimated using 300 and $1,000 \mathrm{~m}$ buffers (Appendix S11). Fragmentation changed with elevation but following a hump pattern that peaked 


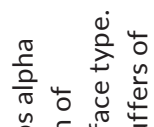

.气 든

동ㅇㅇ응

둥 공

凹

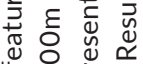

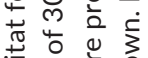

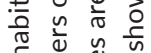

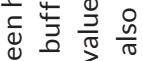

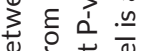

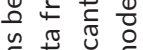

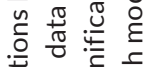

苋造㻤

离

.$\frac{5}{3} \frac{5}{0} \cdot \frac{5}{3}$

.

苋 ⿺辶

ट

节专 $\frac{5}{3}$

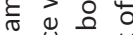

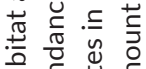

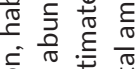

음

莕

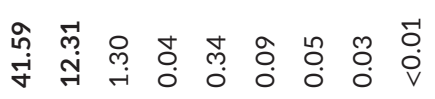
过

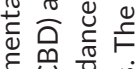

就号

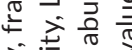

产产

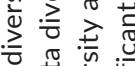

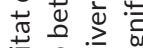

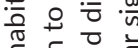

달

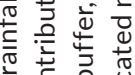

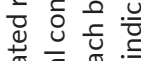

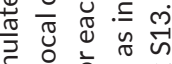

है은 후

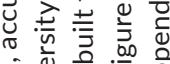

ธิ

茾

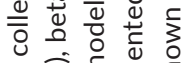

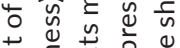

䒕

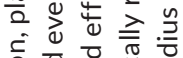

흘 멍

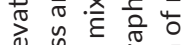

ठ

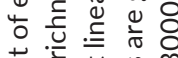

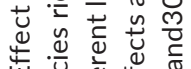

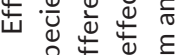

- 은

山

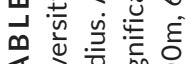

近: 吾

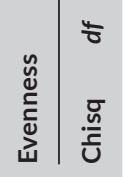
Y

㞧

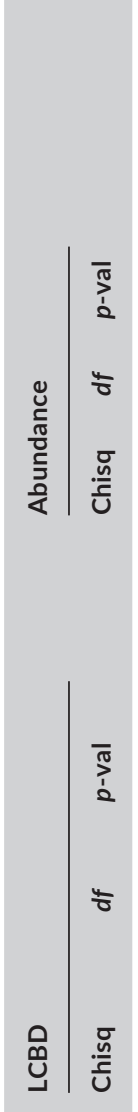

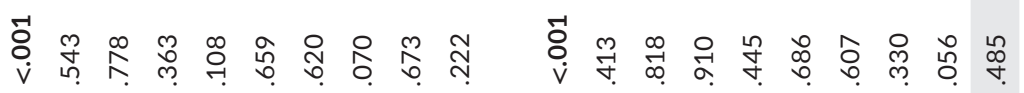

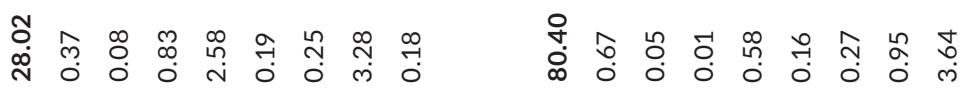
q จ

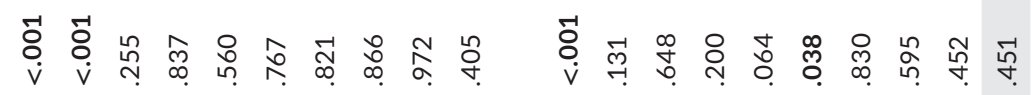

$$
\circ
$$

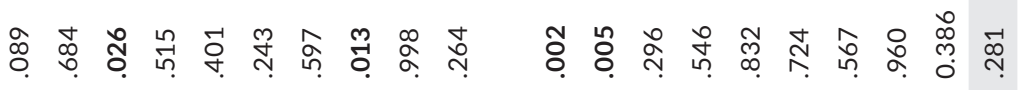

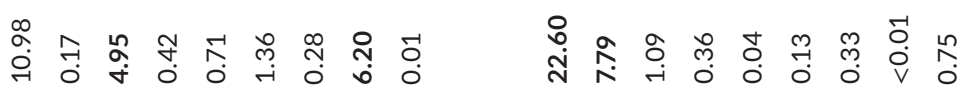

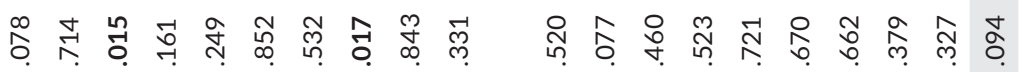

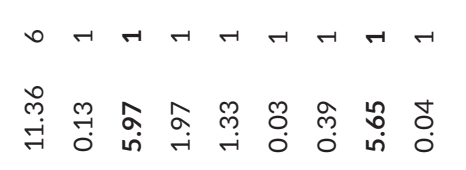

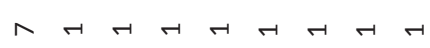

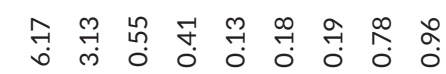

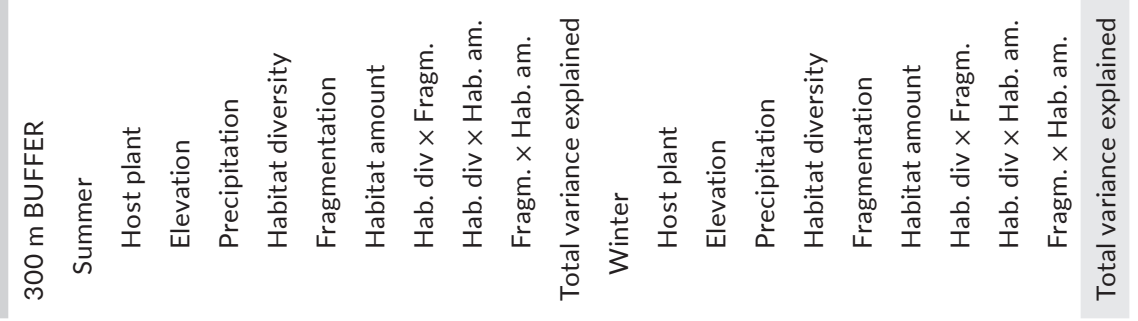




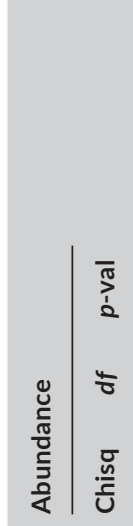

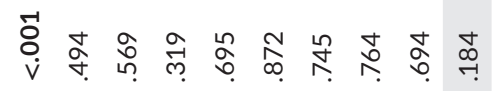

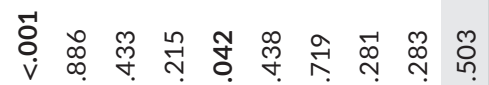

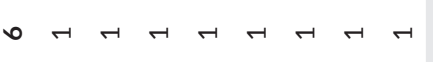

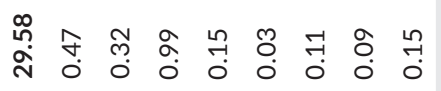

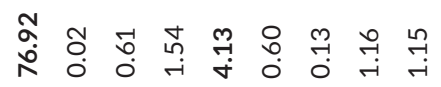
$\bar{F}$

$\vec{\forall}$

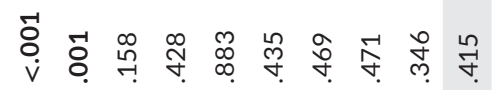

ปे

t)

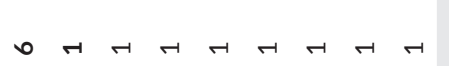

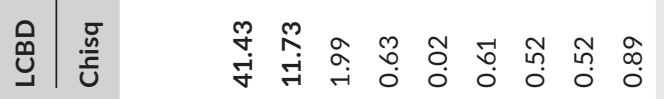

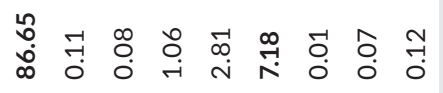
ร

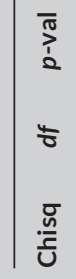

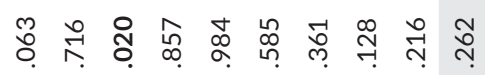

ণิ

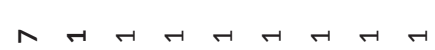
ঔ

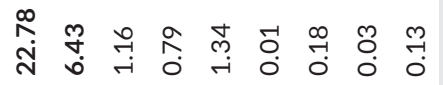
ن

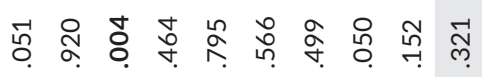

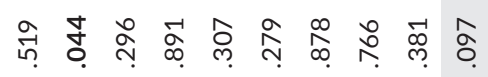

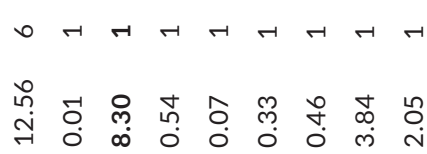

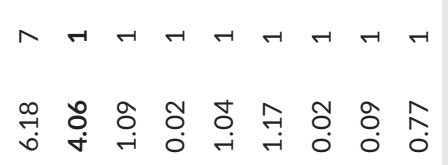


between 500 and 1,000 m.a.s.I., although fragmentation values were larger at elevations below 500 than above 1,000 m.a.s.l. The amount of habitat increased steeply from 0 to 400 m.a.s.l and then a plateau was reached, whereas habitat diversity decreased gradually with elevation. These two opposing effects probably reflect the dominance of natural forests at higher elevations, leading to a larger proportion of habitat available, but to a lower habitat diversity (or evenness).

In the multi-scale analysis, the deviance explained by the different landscape features varied greatly among landscape features and diversity metrics, and none of the buffer sizes used explained model variation greater than the others (Appendix S12). Based on this result, it was not possible to identify the buffer at which spatial effects were strongest and models were therefore built using landscape data from two different buffer sizes that may explain short and long-scale effects, 300 and 1,000 m, respectively (Table 1, but see Appendix S13 for analyses using the other three buffer sizes).

\section{4 | Plant effects on insect diversity and abundance}

The plant from which insects were collected was the variable with the strongest effect on insect evenness, beta diversity and abundance (Table 1, Figure 2). The plants H. ambavilla and L. camara had particularly large values of thrips evenness, $D$. ficulnea, $H$. ambavilla and Ipomoea sp. had the most different thrips assemblages (i.e. largest values of LCBD), whereas D. ficulnea, Ipomoea sp. and S. mauritianum were the plants from where the largest insect abundances were obtained. Species richness was only marginally affected by the plant in summer when using landscape data in the buffer of 1,000 m (Table 1). L. camara was the plant that contained the richest insect assemblage.

\section{5 | Effect of elevation and rainfall on insect diversity and abundance}

Of the different environmental variables considered, only rainfall was retained in the models because temperature was strongly correlated $(R<95 \%)$ with elevation (Appendix S5). In agreement with our hypotheses, elevation had a negative effect on insect alpha and beta diversity (Figure 3; Table 1). When models were built with data from $300 \mathrm{~m}$ buffers, the effect was observed in winter on species evenness (Table 1; Figure 4a). This effect was also observed on richness and evenness in winter when models were built with data from 1,000 $\mathrm{m}$ buffers (Table 1; Figure $4 \mathrm{~g}$ and $\mathrm{h}$ ). Elevation correlated negatively with beta diversity (LCBD) in summer in models using data from both 300 and 1,000 m buffers (Table 1, Figure 4b and i). These results suggest that in Reunion Island thrips are richer, and the different species are more evenly represented and unique in lowlands. Rainfall had a negative effect on thrips species richness and evenness in the models built with landscape data from both 300 and
$1,000 \mathrm{~m}$ buffers. This effect, however, was only observed in summer (Table 1; Figure 4c and j).

\section{Effect of fragmentation, habitat diversity and habitat amount on insect diversity and abundance}

In winter, when including landscape data from both 300 or $1,000 \mathrm{~m}$ buffers, beta diversity and habitat amount related negatively (Table 1, Figure 4d and I). In the models built using data from 1,000 $\mathrm{m}$ buffers, insect abundance related positively with fragmentation in winter (Table 1, Figure 4k). In summer, and when using landscape data from $300 \mathrm{~m}$ buffers, for both species richness and evenness significant interactions between habitat amount and habitat diversity were found (Table 1). In both cases, interaction plots revealed that habitat amount had a positive effect on insect richness and evenness, but this effect was lost in areas of low habitat diversity (Figure $4 \mathrm{e}$ and $\mathrm{f}$ ). This effect was not observed in winter.

\section{7 | DISCUSSION}

In agreement with our hypotheses, insect richness and evenness decreased with elevation, although the effect was only observed in winter. In summer, accumulated monthly rainfall was the abiotic variable that dominated over thrips alpha diversity with a negative effect too. These contrasting seasonal effects may reflect the environmental conditions that dominate these two seasons. In the Indian Ocean, summer is rainy, warm and often with violent cyclones that may wash away adult thrips, an impact already observed by Boissot, Reynaud, and Letourmy (1998) in this same area. In winter, however, low temperatures are likely to be the most important factor reducing alpha diversity at high elevations. As in many other insects in the tropics (Kishimoto-Yamada \& Itioka, 2015), abiotic variables are therefore important factors determining diversity patterns in our study. Insect beta diversity also decreased with elevation in summer, a result that we hypothesized. This effect is unlikely to be caused by the presence or absence of few influential species, or sampling effects because the effect was found in areas with particularly large insect richness. It is surprising, however, that in a hotspot of diversity like Reunion, lowland habitats that are dominated by invasive plant species (like L. camara) and urbanization (Strasberg et al., 2005) host the most diverse and unique thrips assemblages. Many studies have already reported similar correlations between human populations and diversity (Luck, 2007) probably because human populations concentrate in areas with larger annual energy budgets that lead to more benign conditions for organisms to thrive (Gaston, 2005). Thrips fauna in the Indian Ocean is poorly studied, and it is therefore difficult to know whether these lowland thrips assemblages are dominated by exotic species that reached the island together with exotic plants, or by native insects. The former is a likely situation because invasive insects often reach new territories together 

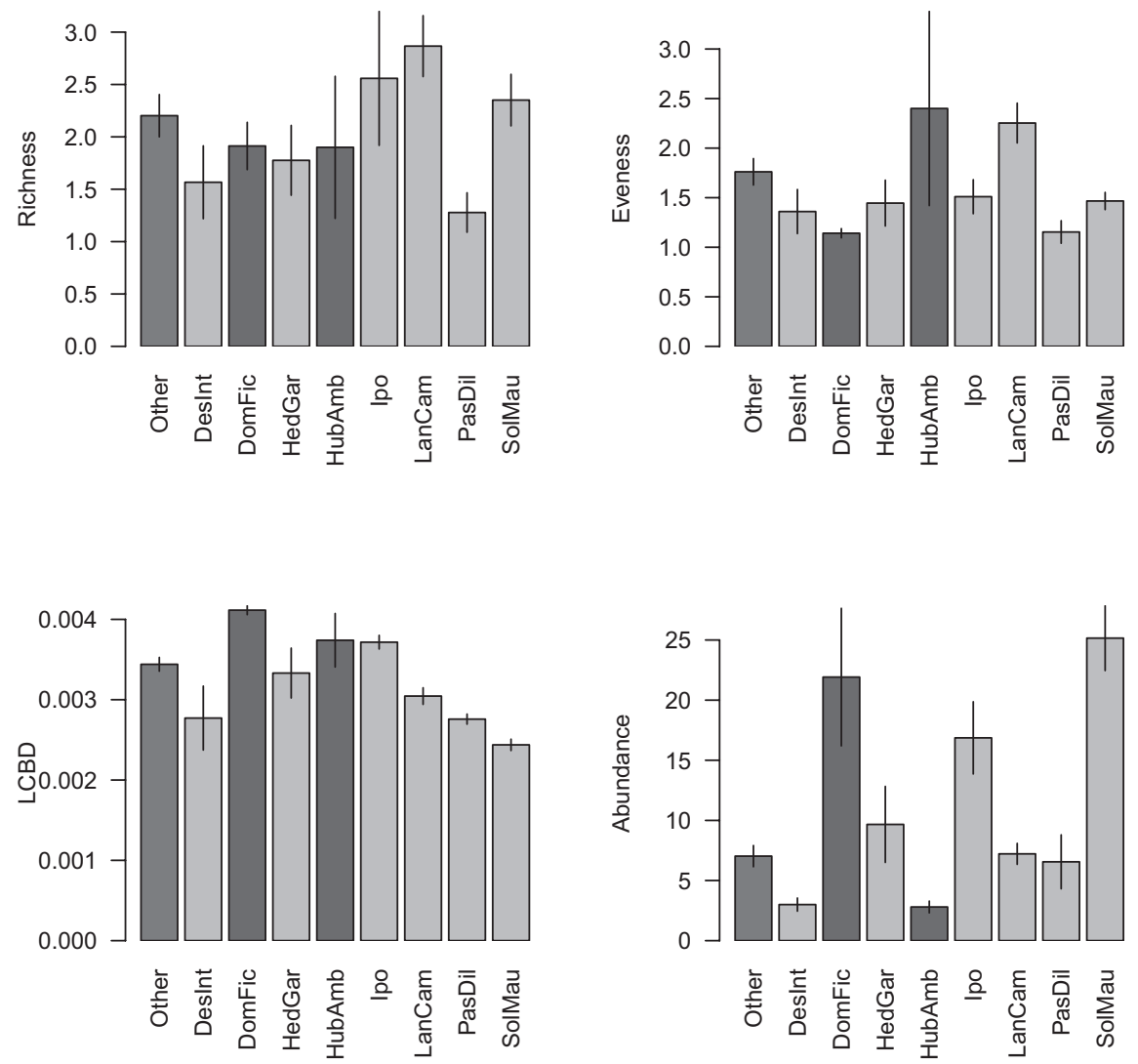

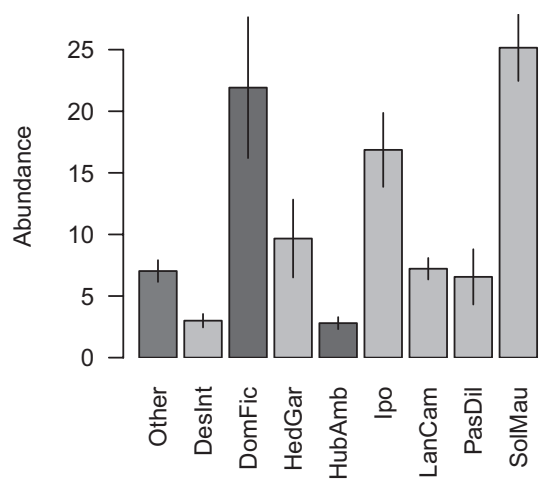

FIGURE 2 Thrips diversity and abundance on the different plants studied. Alpha diversity is expressed as species richness and evenness (Simpson index), and beta diversity as the local contribution to beta diversity metric (LCBD). Dark and light grey bars represent endemic and exotic plants, respectively. The category "others" includes plants that were sampled less than five times during the study. Abbreviations represent the following plants: Desmodium intortum (DesInt), Dombeya ficulnea (DomFic), Hedychium gardnerianum (HedGar), Hubertia ambavilla (HubAmb), Ipomoea spp. (Ipo), Lantana camara (LanCam), Paspalum dilatatum (PasDil) and Solanum mauritianum (SolMau). Details on the plants sampled can be found in Appendix s06. with their host plants (Liebhold, Brockerhoff, Garrett, Parke, \& Britton, 2012). Knowing where native thrips are located would be particularly useful to identify hotspots of endemic diversity within the island (Socolar et al., 2016), and to unveil the role that invasive plants played in determining insect diversity patterns.

Thrips diversity was influenced by landscape features, when extracting landscape information from 300 and 1,000 m buffers. This suggests that these minute insects are able to disperse large distances as has already been reported for some species (Mound, 2005). In summer, both species richness and evenness were significantly related to habitat amount, but this effect depended on habitat diversity. The relationship between habitat amount and insect diversity was positive in highly diverse landscapes, but this effect was offset in areas of low diversity. In agreement with our hypotheses, the negative effect of habitat loss on insect diversity may be thus exacerbated in low diversity habitats. In a recent study, Corcos et al. (2018) explored whether the effect of temperature on the diversity of a range of different insect guilds was modulated by habitat diversity along elevational gradients. These authors found contrasting effects on the different insect guilds studied, but the interaction between landscape and elevation was never significant. As done by these authors, our measure of habitat diversity was based on the proportion of different habitat types within the buffer, also known as land cover diversity. This measure mainly expresses topographic heterogeneity, and a meta-analysis by Stein et al. (2014) revealed its strong effect on the richness of terrestrial plants and animals. In this meta-analysis, however, plant diversity and vegetation complexity also had strong impacts on diversity. Studies with cavity-nesting bees and wasps (Staab et al., 2016), and with insect predators (Vehviläinen, Koricheva, \& Ruohomäki, 2008), for instance, revealed that diversity at the plant layer can even cascade up to higher trophic levels, and that the effect may depend on plant composition and on phylogenetic diversity [reviewed in (Moreira, Abdala-Roberts, Rasmann, Castagneyrol, \& Mooney, 2015)]. It would be very interesting to obtain more detailed information from our study sites, and to explore how other habitat diversity measures affect the results obtained. Relative to lowlands, highlands in Reunion had the lowest habitat diversity values because these areas are uniformly dominated by natural forests. These habitats, however, are likely to be far more diverse in terms of plant richness so the results observed here may be reversed. Going deeper into the diversity of our study sites, for example exploring plant diversity, may also help to understand the unexpected negative effect that habitat amount had on beta diversity. Exploring the effect of plant diversity may require expertise in plant taxonomy and intense fieldwork, and using highly-resolved landscape layers is likely to be the most feasible technique in areas where plant taxonomy is not fully resolved, or fieldwork is challenging. The method used here can therefore be useful to compare our results with other animal taxa because few studies have integrated a suite of landscape variables to identify and isolate the factors that drive alpha and beta diversity changes along environmental gradients (Mori et al., 2018).

There is a long and unsolved debate over whether fragmentation has a positive or negative effect on diversity (Fahrig, 2019; Fletcher et al., 2018), and on whether negative effects are mostly 


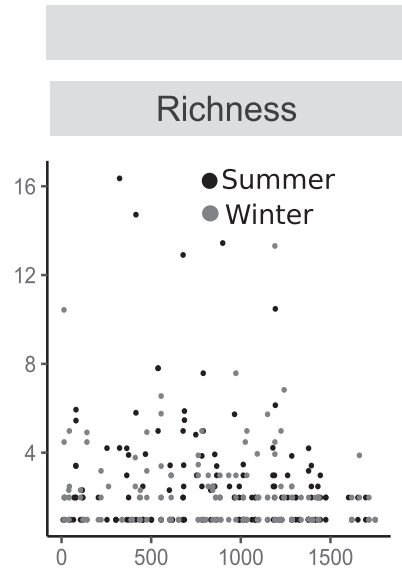

\section{Ordinate axis label}
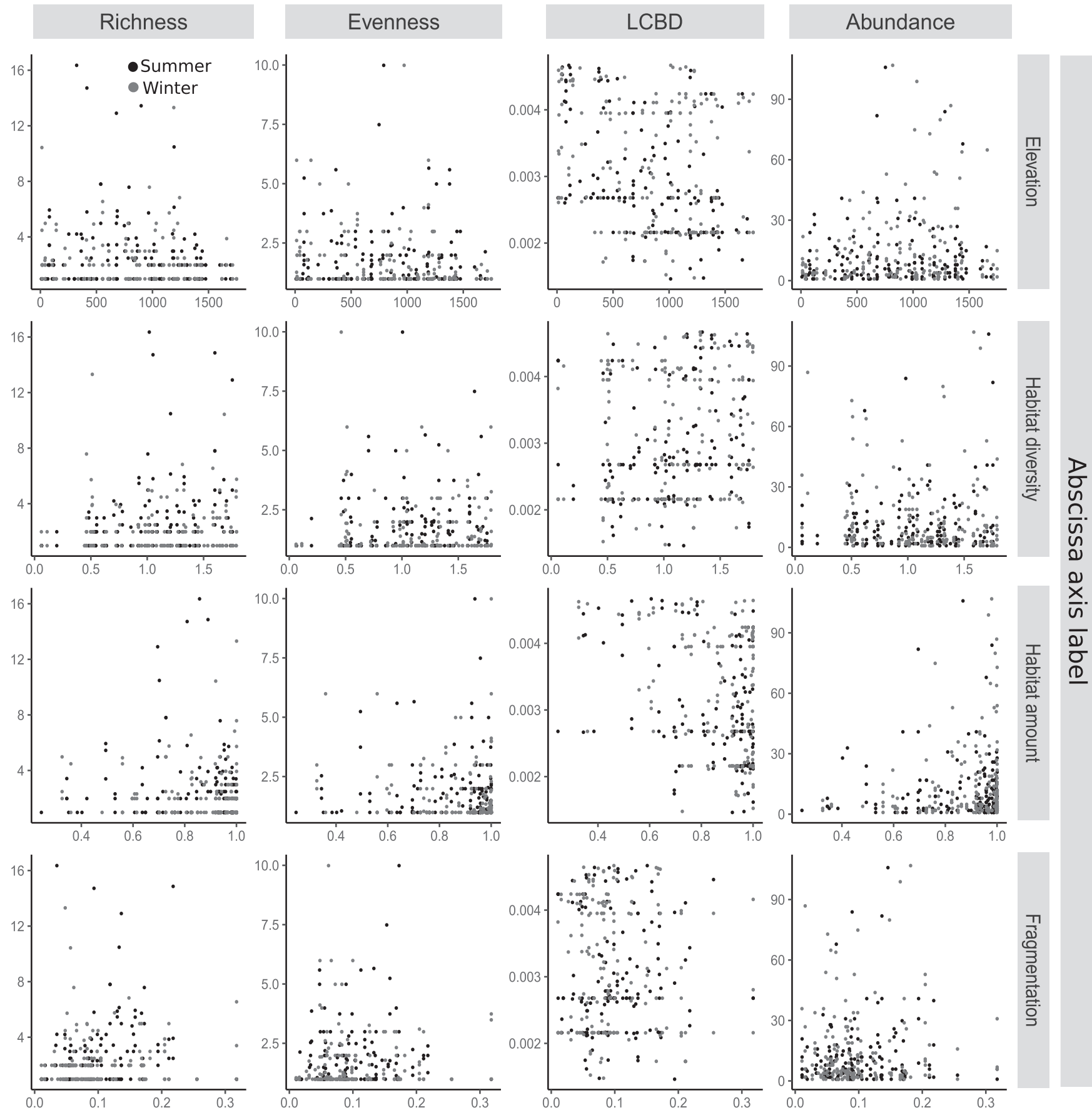

FIGURE 3 Scaterplots showing the relationship between elevation and landscape features with the different metrics of thrips diversity and abundance. Alpha diversity is expressed as species richness and evenness (Simpson index), and beta diversity as the local contribution to beta diversity metric (LCBD). Landscape features are estimated using $1000 \mathrm{~m}$ buffers. Black and grey dots represent values estimated in summer and winter, respectively.

due to a reduction in the amount of habitat available. In our study, fragmentation had a positive effect on thrips total abundance in winter, but overall this variable had little influence on diversity estimates. Relative to habitat amount or habitat diversity, fragmentation is therefore a minor driver of thrips diversity in Reunion Island. In addition, if the models built are simplified and habitat amount removed (results not shown), fragmentation becomes a significant explanatory variable for diversity in some cases, which suggests that habitat amount may sometimes be the reason behind significant effects of fragmentation on diversity. Altogether, these results provide additional support to the habitat amount hypothesis (Fahrig, 2013; Watling et al., 2020), although more experimental work, and not just observational studies is needed to confirm this tendency over a range of taxa and ecosystem types. 


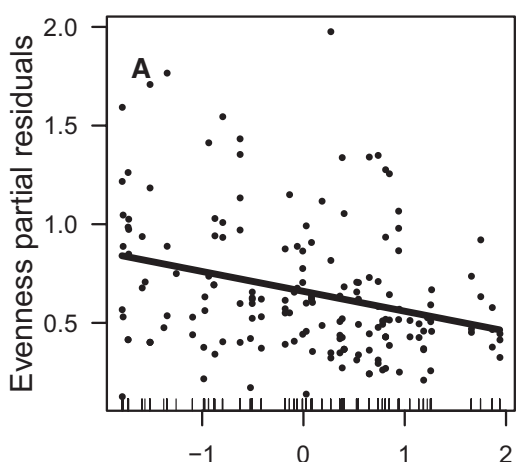

Standardised elevation

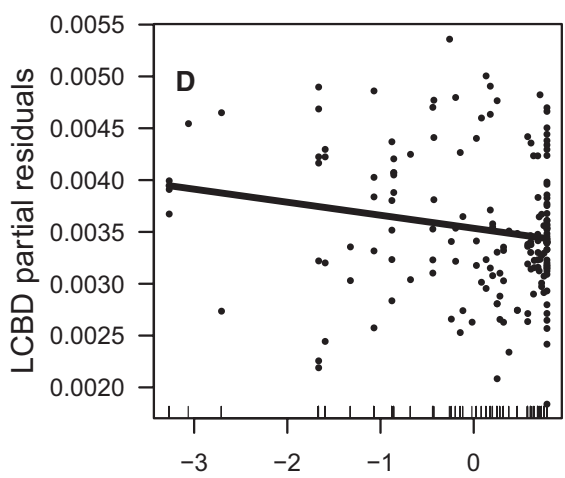

Standardised habitat amount

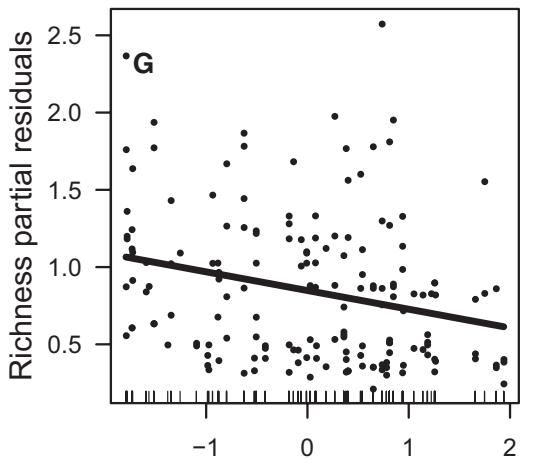

Standardised elevation

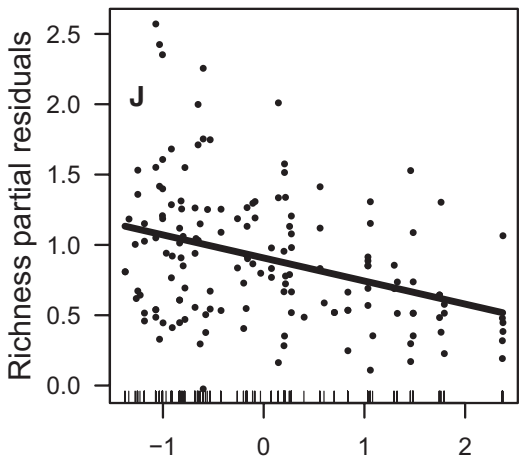

Standardised rainfall

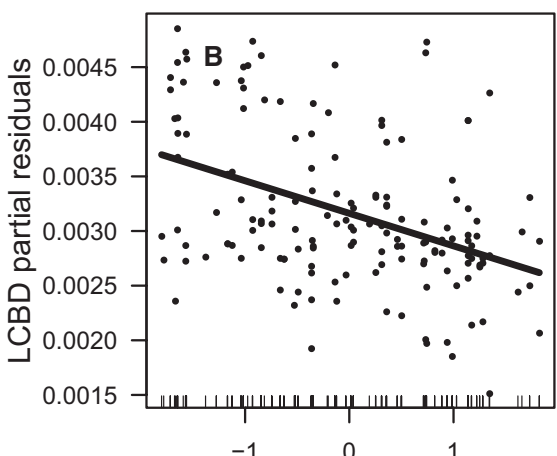

Standardised elevation

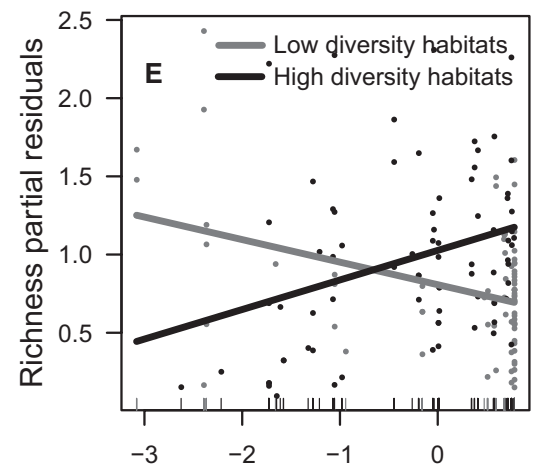

Standardised habitat amount

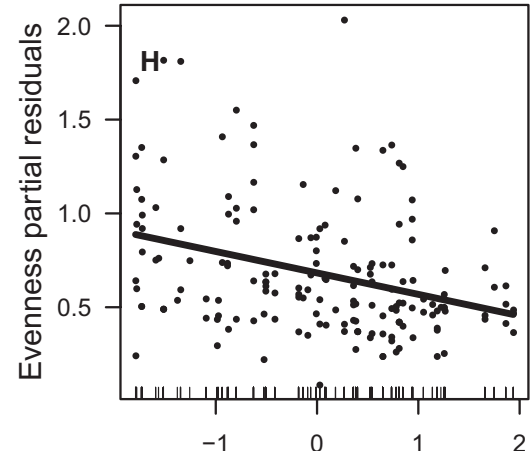

Standardised elevation

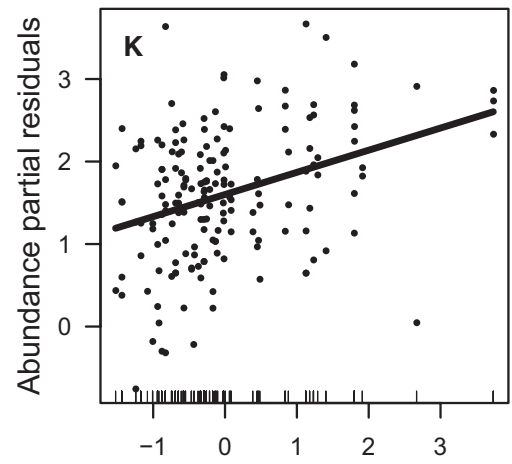

Standardised fragmentation
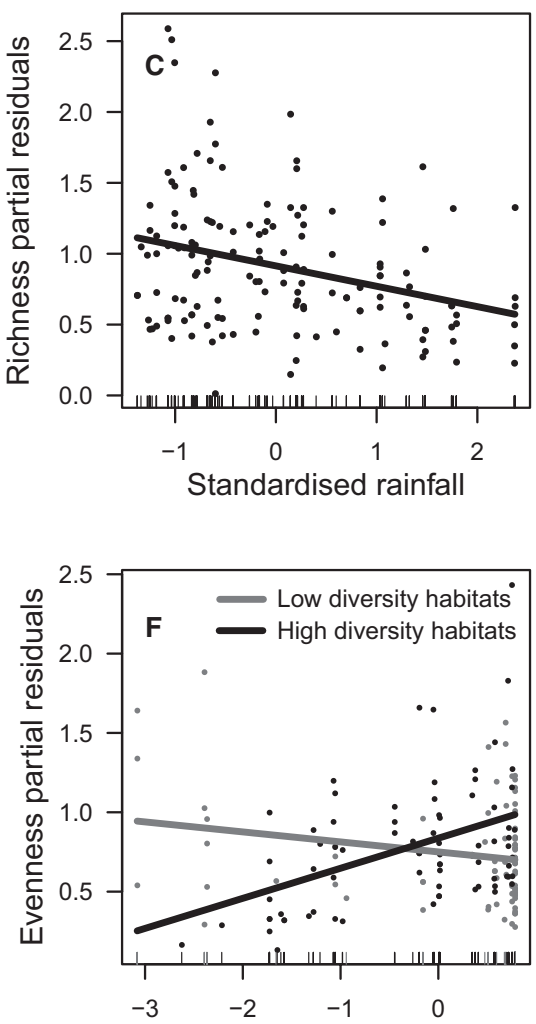

Standardised habitat amount

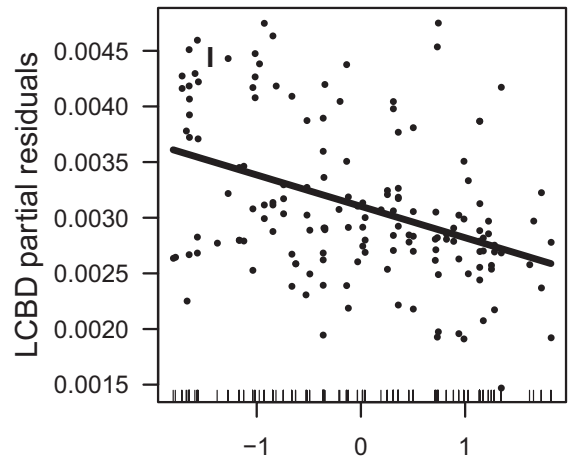

Standardised elevation

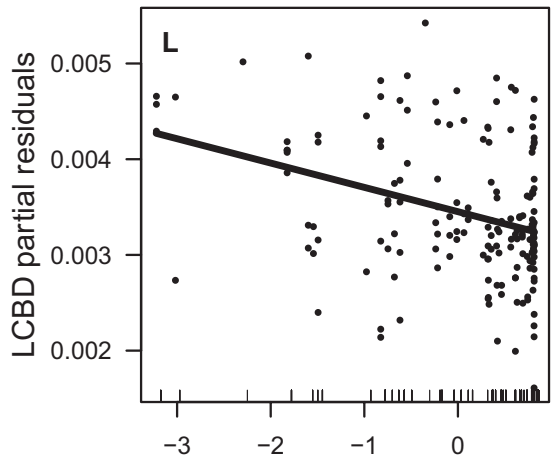

Standardised habitat amount
Our diversity estimates were based on adult thrips collected from flowers, but their larvae are known to predate on other insects, or to feed on a variety of plants and fungi, and then to disperse as adults to feed on pollen or to mate (Mound, 2005). Thrips are easy to sample and have a large functional and taxonomic diversity, which makes this insect order a good model to study diversity patterns. Even if some 
FIGURE 4 Plots showing partial residuals from the models on the effect of elevation, rainfall and landscape variables on thrips diversity and abundance when extracting landscape information from 300m (A-F) and 1000m (G-L) buffers. Only significant effects are plotted (see Table 1). The fitted lines are estimated from the linear mixed effects models, the points represent the partial residuals from the models, based on the visreg package in $\mathrm{R}$, and the rugplot is shown along the abscissa axis. To fulfil model assumptions all analyses are performed after standardising all predictor continuous variables. A. The effect of elevation on thrips evenness in winter; B. The effect of elevation on thrips beta diversity (LCBD) in summer; $C$. The effect of accumulated rainfall on thrips species richness in summer; $D$. The effect of habitat amount on thrips beta diversity (LCBD) in winter. The effect of habitat amount and its interactions with habitat diversity on thrips species richness (E) and evenness (F) in summer. The interaction represents high (dark grey) and low (light grey) values of habitat diversity; The effect of elevation on thrips species richness $(\mathrm{G})$ and evenness $(\mathrm{H})$ in winter; I. The effect of elevation on thrips beta diversity (LCBD) in summer; $J$. The effect of accumulated rainfall on thrips species richness in summer; $K$. The effect of fragmentation on thrips abundance in winter; $L$. The effect of habitat amount on thrips beta diversity (LCBD) in winter. For both the models built using landscape data from 300 and $1000 \mathrm{~m}$, the significant effect of accumulated rainfall on thrips evenness in summer has been omitted as the relationship is very similar to that with species richness. Raw data ranges can be seen in Figure 3.

thrips species are known to be pollinators, this group is not usually considered as a pollinator guild, and most species are considered as passive dispersers with weak interactions with flowers as adults (Mound, 2005). The multivariate analysis revealed that plants had a strong effect on thrips composition, thereby suggesting that this group can also be useful to study insect-plant interaction networks. For example, the newly found species, T. reunionensis (Goldarazena et al., 2020) was associated with the endemic plant Dombeya ficulnea, but only in winter when this plant was in full bloom.

One reason why the elevational diversity gradient in herbivores is not fully understood is that it depends on several interacting factors. Several environmental variables are hypothesized to be the driving force, but also their indirect effect via primary productivity and competitive interactions (Kreft \& Jetz, 2007; Vetaas, Paudel, \& Christensen, 2019). Many hypotheses like the mid domain effect or the water-energy dynamics have been proposed. As we show here, finding general patterns may be challenging if habitat disturbance by human populations is not taken into account. Reunion is a small island in which the landscape changes dramatically with elevation because human settlements concentrate in lowlands, a large national park covers high elevation areas, and agricultural lands are found in between with strong differences between the east and the west of the island (Strasberg et al., 2005). Even if some landscape variables like habitat amount were collinear with elevation, elevation impacted the different habitat features measured differently. This situation offered a unique opportunity to explore how, in addition to elevation, landscape features affect diversity patterns. Island diversity, especially in highly populated and remote islands like Reunion, is particularly threatened by habitat loss and invasive species. Given the disproportionate diversity that tropical islands host, understanding how diversity varies across space and time in these areas can help designing future conservation efforts (Russell \& Kueffer, 2019). Many thrips species are pests, and studying the diversity of this taxa can also help to understand their spatio-temporal dynamics and allow the design of agricultural landscapes in which pest outbreaks are less likely.

\section{ACKNOWLEDGEMENTS}

We are grateful to Samuel Nibouche for insightful discussions along the development of this project, to Gérard Lebreton and Eric Rivière (Pôle Forêt, Saint-Pierre) for help with plant identification, to Bruno Michel and Arturo Goldarazena for help with thrips identification, and to Christine Meynard, the many members of N.T.D's $\mathrm{PhD}$ committee, and two anonymous reviewers for insightful comments on earlier versions of the manuscript. This work was funded by the Regional Council of Reunion, the Departmental Council of the Region Reunion, the European Union (EAFRD and ERDF programs) and by the Centre de Coopération internationale en Recherche agronomique pour le Développement (CIRAD). N.T.D. was funded by Regional Council of Reunion via a PhD scholarship. EF was funded by the Regional Council of Reunion, the Departmental Council of the Region Reunion, the European Union (EAFRD), CIRAD and the Agence Nationale de la Recherche (ANR) via the PRIMA S2 2018 project INTOMED.

\section{DATA AVAILABILITY STATEMENT}

The data sets generated during and/or analysed during the current study are available at Dryad doi:10.5061/dryad.18931zcvk. R code used to analyse data can be accessed from the corresponding author on reasonable request.

\section{ORCID}

Enric Frago (iD https://orcid.org/0000-0001-8817-1303

\section{REFERENCES}

Barnosky, A. D., Matzke, N., Tomiya, S., Wogan, G. O. U., Swartz, B., Quental, T. B., ... Ferrer, E. A. (2011). Has the Earth's sixth mass extinction already arrived? Nature, 471(7336), 51-57. https://doi. org/10.1038/nature09678

Bates, D., Mächler, M., Bolker, B. M., \& Walker, S. C. (2015). Fitting linear mixed-effects models using Ime4. Journal of Statistical Software, 67(1), 1-48. https://doi.org/10.18637/jss.v067.i01

Benjamini, Y., \& Hochberg, Y. (1995). Controlling the false discovery rate-A practical and powerful approach to multiple testing. Journal of the Royal Statistical Society Series B (Methological), 57(1), 289-300. https://doi.org/10.2307/2346101

Bertrand, C., Burel, F., \& Baudry, J. (2016). Spatial and temporal heterogeneity of the crop mosaic influences carabid beetles in agricultural landscapes. Landscape Ecology, https://doi.org/10.1007/s1098 0-015-0259-4

Betts, M. G., Fahrig, L., Hadley, A. S., Halstead, K. E., Bowman, J., Robinson, W. D., ... Lindenmayer, D. B. (2014). A species-centered approach for uncovering generalities in organism responses to habitat loss and fragmentation. Ecography, 37(6), 517-527. https://doi. org/10.1111/ecog.00740 
Boissot, N., Reynaud, B., \& Letourmy, P. (1998). Temporal analysis of western flower thrips (Thysanoptera: Thripidae) population dynamics on reunion island. Environmental Entomology, 27(6), 1437-1443. https://doi.org/10.1093/ee/27.6.1437

Cardinale, B. J., Duffy, J. E., Gonzalez, A., Hooper, D. U., Perrings, C., Venail, P., ... Naeem, S. (2012). Biodiversity loss and its impact on humanity. Nature, 486(7401), 59-67. https://doi.org/10.1038/nature11148

Chamberlain, D., Brambilla, M., Caprio, E., Pedrini, P., \& Rolando, A. (2016). Alpine bird distributions along elevation gradients: The consistency of climate and habitat effects across geographic regions. Oecologia, 181(4), 1139-1150. https://doi.org/10.1007/ s00442-016-3637-y

Chao, A., Gotelli, N. J., Hsieh, T. C., Sander, E. L., Ma, K. H., Colwell, R. K., \& Ellison, A. M. (2014). Rarefaction and extrapolation with Hill numbers: A framework for sampling and estimation in species diversity studies. Ecological Monographs, 84(1), 45-67. https://doi. org/10.1890/13-0133.1

Chao, A., \& Jost, L. (2012). Coverage-based rarefaction and extrapolation: Standardizing samples by completeness rather than size. Ecology, 93(12), 2533-2547. https://doi.org/10.1890/11-1952.1

Colwell, R. K., Chao, A., Gotelli, N. J., Lin, S. Y., Mao, C. X., Chazdon, R. L., \& Longino, J. T. (2012). Models and estimators linking individual-based and sample-based rarefaction, extrapolation and comparison of assemblages. Journal of Plant Ecology, 5(1), 3-21. https://doi. org/10.1093/jpe/rtr044

Corcos, D., Cerretti, P., Mei, M., Vigna Taglianti, A., Paniccia, D., Santoiemma, G., ... Marini, L. (2018). Predator and parasitoid insects along elevational gradients: Role of temperature and habitat diversity. Oecologia, 188(1), 193-202. https://doi.org/10.1007/s0044 2-018-4169-4

Fahrig, L. (2013). Rethinking patch size and isolation effects: The habitat amount hypothesis. Journal of Biogeography, 40(9), 1649-1663. https://doi.org/10.1111/jbi.12130

Fahrig, L. (2017). Ecological responses to habitat fragmentation per se. Annual Review of Ecology Evolution and Systematics, 48, 447-471. https://doi.org/10.1146/annurev-ecolsys-110316

Fahrig, L. (2019). Habitat fragmentation: A long and tangled tale. Global Ecology and Biogeography, 28(1), 33-41. https://doi.org/10.1111/ geb.12839

Fletcher, R. J., Didham, R. K., Banks-Leite, C., Barlow, J., Ewers, R. M., Rosindell, J., ... Haddad, N. M. (2018). Is habitat fragmentation good for biodiversity? Biological Conservation, 226, 9-15. https://doi. org/10.1016/j.biocon.2018.07.022

Gaston, K. J. (2005). Biodiversity and extinction: Species and people. Progress in Physical Geography, 29(2), 239-247. https://doi. org/10.1191/0309133305pp445pr

Goldarazena, A., Dianzinga, N. T., Frago, E., Michel, B., \& Reynaud, P. (2020). A new species of the Genus Thrips (Thysanoptera, Thripidae) from the Afro-tropical Region. Zootaxa, 4750(3), 443-446.

Haddad, N. M., Brudvig, L. A., Clobert, J., Davies, K. F., Gonzalez, A., Holt, R. D., ... Townshend, J. R. (2015). Habitat fragmentation and its lasting impact on Earth's ecosystems. Science Advances, 1(2), e1500052. https://doi.org/10.1126/sciadv.1500052

Haila, Y., \& Hanski, I. K. (1984). Methodology for studying the effect of habitat fragmentation on land birds. Annales Zoologici Fennici.21(3), 393-397.

Hanski, I. (2015). Correspondence-Habitat fragmentation and species richness. Journal of Biogeography, 42(5), 989-993. Retrieved from http://onlinelibrary.wiley.com/doi/10.1111/jbi.12478/full.

Harrison, X. A., Donaldson, L., Correa-Cano, M. E., Evans, J., Fisher, D. N., Goodwin, C. E. D., ... Inger, R. (2018). A brief introduction to mixed effects modelling and multi-model inference in ecology. PeerJ, 6, e4794. https://doi.org/10.7717/peerj.4794

Harter, D. E. V., Irl, S. D. H., Seo, B., Steinbauer, M. J., Gillespie, R., Triantis, K. A., ... Beierkuhnlein, C. (2015). Impacts of global climate change on the floras of oceanic islands - Projections, implications and current knowledge. Perspectives in Plant Ecology, Evolution and Systematics, 17(2), 160-183. https://doi.org/10.1016/j.ppees.2015.01.003

Hodkinson, I. D. (2005). Terrestrial insects along elevation gradients: Species and community responses to altitude. Biological Reviews of the Cambridge Philosophical Society, 80(3), 489-513. https://doi. org/10.1017/S1464793105006767

Hooper, D. U., Adair, E. C., Cardinale, B. J., Byrnes, J. E. K., Hungate, B. A., Matulich, K. L., ... O'Connor, M. I. (2012). A global synthesis reveals biodiversity loss as a major driver of ecosystem change. Nature, 486(7401), 105-108. https://doi.org/10.1038/nature11118

IUCN. (2008). World Heritage Nomination - IUCN technical evaluation, Pitons, cirques and Remparts of Reunion Island (France) - ID No 1317.

Jackson, H. B., \& Fahrig, L. (2015). Are ecologists conducting research at the optimal scale? Global Ecology and Biogeography, 24(1), 52-63. https://doi.org/10.1111/geb.12233

Jost, L. (2006). Entropy and diversity. Oikos, 113(2), 363-375. https://doi. org/10.1111/j.2006.0030-1299.14714.x

Kishimoto-Yamada, K., \& Itioka, T. (2015). How much have we learned about seasonality in tropical insect abundance since Wolda (1988)? Entomological Science, 18(4), 407-419. https://doi.org/10.1111/ens.12134

Kreft, H., \& Jetz, W. (2007). Global patterns and determinants of vascular plant diversity. Proceedings of the National Academy of Sciences, 104(14), 5925-5930. https://doi.org/10.1073/pnas.0608361104

Kremen, C., \& Merenlender, A. M. (2018). Landscapes that work for biodiversity and people. Science, 362(6412), eaau6020. https://doi. org/10.1126/science.aau6020

Legendre, P., \& Anderson, M. J. (1999). Distance-based redundancy analysis: Testing multispecies responses in multifactorial ecological experiments. Ecological Monographs, 69, 1-24.

Legendre, P., \& De Cáceres, M. (2013). Beta diversity as the variance of community data: Dissimilarity coefficients and partitioning. Ecology Letters, 16, 951-963.

Legendre, P., \& Gallagher, E. D. (2001). Ecologically meaningful transformations for ordination of species data. Oecologia, 129, 271-280.

Liebhold, A. M., Brockerhoff, E. G., Garrett, L. J., Parke, J. L., \& Britton, K. O. (2012). Live plant imports: The major pathway for forest insect and pathogen invasions of the US. Frontiers in Ecology and the Environment, https://doi.org/10.1890/110198

Luck, G. W. (2007). A review of the relationships between human population density and biodiversity. Biological Reviews, 82(4), 607-645. https://doi.org/10.1111/j.1469-185X.2007.00028.x

Mantyka-pringle, C. S., Martin, T. G., \& Rhodes, J. R. (2012). Interactions between climate and habitat loss effects on biodiversity: A systematic review and meta-analysis. Global Change Biology, 18(4), 12391252. https://doi.org/10.1111/j.1365-2486.2011.02593.x

Marini, L., Prosser, F., Klimek, S., \& Marrs, R. H. (2008). Waterenergy, land-cover and heterogeneity drivers of the distribution of plant species richness in a mountain region of the European Alps. Journal of Biogeography, 35(10), 1826-1839. https://doi. org/10.1111/j.1365-2699.2008.01924.x

McCain, C. M. (2009). Global analysis of bird elevational diversity. Global Ecology and Biogeography, 18(3), 346-360. https://doi. org/10.1111/j.1466-8238.2008.00443.x

Moreira, X., Abdala-Roberts, L., Rasmann, S., Castagneyrol, B., \& Mooney, K. A. (2015). Plant diversity effects on insect herbivores and their natural enemies: Current thinking, recent findings, and future directions. Current Opinion in Insect Science, 32, 15-21. https:// doi.org/10.1016/j.cois.2015.10.003

Mori, A. S., Isbell, F., \& Seidl, R. (2018). $\beta$-Diversity, community assembly, and ecosystem functioning. Trends in Ecology and Evolution, 33(7), 549-564. https://doi.org/10.1016/j.tree.2018.04.012

Mound, L. A. (2005). Thyssanoptera: Diversity and interactions. Annual Review of Entomology, 50(6), 247-269. https://doi.org/10.1146/annur ev.ento.49.061802.123318 
Russell, J. C., \& Kueffer, C. (2019). Island biodiversity in the anthropocene. Annual Review of Environment and Resources, 44(1), 31. https:// doi.org/10.1146/annurev-environ-101718-033245

Rybicki, J., Abrego, N., \& Ovaskainen, O. (2020). Habitat fragmentation and species diversity in competitive communities. Ecology Letters, 23(3), 506-517. https://doi.org/10.1111/ele.13450

Samways, M. J., McGeoch, M. A., \& New, T. R. (2010). Insect conservation: A handbook of approaches and methods, UK: Oxford University.

Schielzeth, H., Dingemanse, N. J., Nakagawa, S., Westneat, D. F., Allegue, H., Teplitsky, C., ... Araya-Ajoy, Y. G. (2020). Robustness of linear mixed-effects models to violations of distributional assumptions. Methods in Ecology and Evolution, https://doi.org/10.1111/2041-210x.13434

Socolar, J. B., Gilroy, J. J., Kunin, W. E., \& Edwards, D. P. (2016). How should beta-diversity inform biodiversity conservation? Trends in Ecology and Evolution, 31(1), 67-80. https://doi.org/10.1016/j. tree.2015.11.005

Staab, M., Bruelheide, H., Durka, W., Michalski, S., Purschke, O., Zhu, C. D., \& Klein, A. M. (2016). Tree phylogenetic diversity promotes host-parasitoid interactions. Proceedings of the Royal Society B: Biological Sciences, 283(1834), 20160275. https://doi.org/10.1098/ rspb.2016.0275

Stein, A., Gerstner, K., \& Kreft, H. (2014). Environmental heterogeneity as a universal driver of species richness across taxa, biomes and spatial scales. Ecology Letters, 17(7), 866-880. https://doi.org/10.1111/ ele.12277

Steinbauer, M. J., Field, R., Grytnes, J.-A., Trigas, P., Ah-Peng, C., Attorre, F., ... Beierkuhnlein, C. (2016). Topography-driven isolation, speciation and a global increase of endemism with elevation. Global Ecology and Biogeography, 25(9), 1097-1107. https://doi.org/10.1111/ geb.12469

Stork, N. E. (2018). How many species of insects and other terrestrial arthropods are there on earth? Annual Review of Entomology, 63(1), 31-45. https://doi.org/10.1146/annurev-ento-020117-043348

Strasberg, D., Rouget, M., Richardson, D. M., Baret, S., Dupont, J., \& Cowling, R. M. (2005). An assessment of habitat diversity and transformation on La Réunion Island (Mascarene Islands, Indian Ocean) as a basis for identifying broad-scale conservation priorities. Biodiversity and Conservation, 14(12), 3015-3032. https://doi. org/10.1007/s10531-004-0258-2

Sundqvist, M. K., Sanders, N. J., Wardle, D. A. (2013). Community and ecosystem responses to elevational gradients: Processes, mechanisms, and insights for global change. Annual Review of Ecology, Evolution, and Systematics, 44(1), 261-280. https://doi.org/10.1146/ annurev-ecolsys-110512-135750

Tyagi, K., Kumar, V., Singha, D., Chandra, K., Laskar, B. A., Kundu, S. ... Chatterjee, S. (2017). DNA barcoding studies on thrips in India: Cryptic species and species complexes. Scientific Reports, 7(1), 1-14. https://doi.org/10.1038/s41598-017-05112-7

Tylianakis, J. M., \& Morris, R. J. (2017). Ecological networks across environmental gradients. Annual Review of Ecology, Evolution, and Systematics, 48(1), 25-48. https://doi.org/10.1146/annurev-ecols ys-110316-022821
Urban, M. C. (2015). Accelerating extinction risk from climate change. Science, 348(6234), 571-573. https://doi.org/10.1126/science.aaa4984

Vehviläinen, H., Koricheva, J., \& Ruohomäki, K. (2008). Effects of stand tree species composition and diversity on abundance of predatory arthropods. Oikos, 117(6), 935-943. https://doi. org/10.1111/j.0030-1299.2008.15972.x

Vetaas, O. R., \& Grytnes, J. A. (2002). Distribution of vascular plant species richness and endemic richness along the Himalayan elevation gradient in Nepal. Global Ecology and Biogeography, 11(4), 291-301. https://doi.org/10.1046/j.1466-822X.2002.00297.x

Vetaas, O. R., Paudel, K. P., \& Christensen, M. (2019). Principal factors controlling biodiversity along an elevation gradient: Water, energy and their interaction. Journal of Biogeography, 46(8), 1652-1663. https://doi.org/10.1111/jbi.13564

Watling, J. I., Arroyo-Rodríguez, V., Pfeifer, M., Baeten, L., Banks-Leite, C., Cisneros, L. M., ... Fahrig, L. (2020). Support for the habitat amount hypothesis from a global synthesis of species density studies. Ecology Letters, 1-8, https://doi.org/10.1111/ele.1347

\section{BIOSKETCH}

Niry. T. Dianzinga is a PhD student of the University of Reunion based at CIRAD/3P interested in the ecology and taxonomy of thrips and on insect community ecology in general. This $\mathrm{PhD}$ was developed in the team led by Enric Frago who is an insect ecologist interested in insect community ecology, insect-plant-microbe interactions and biocontrol.

Author contributions: N.T.D. and E.F conceived and designed the study; Author contributions: N.T.D., M-L.M. and E.F. collected insects; N.T.D identified insects; J.S. performed the molecular laboratory work; N.T.D. and E.F analysed data and wrote the manuscript with comments from all co-authors.

\section{SUPPORTING INFORMATION}

Additional supporting information may be found online in the Supporting Information section.

How to cite this article: Dianzinga NT, Moutoussamy M-L, Sadeyen J, Ravaomanarivo LHR, Frago E. The interacting effect of habitat amount, habitat diversity and fragmentation on insect diversity along elevational gradients. J Biogeogr. 2020;00:1-15. https://doi.org/10.1111/jbi.13959 